\section{Foliar Auxin Application Improves Adventitious Rooting of Wall Germander Cuttings}

\author{
Benjamin D. Taylor and Benjamin K. Hoover ${ }^{1}$
}

AdDITIONAL INDEX wORDS. IBA, K-IBA, indole-3-butyric acid, ornamental horticulture, plant propagation, Teucrium chamaedrys

SuMmaRY. Indole-3-butyric acid (IBA) is frequently used to promote adventitious root development in plant propagation from cuttings. We evaluated the effects of 0,1000 , or $3000 \mathrm{ppm}$ IBA applied as a liquid foliar spray or talc-based basal dip on adventitious rooting of wall germander (Teucrium chamaedrys) cuttings. An initial experiment was conducted in Fall 2016, followed by a replication in Spring 2017. Two-dimensional root area, primary root count, root dry weight, and a rooting index ( 0 to 5 scale) were assessed as measures of root growth. By all metrics and for both experiments, cuttings benefited from IBA application and exhibited equal or greater root growth after the foliar spray treatment compared with the talc dip. In both experiments and for all metrics, the talc dip method achieved no greater root growth at $3000 \mathrm{ppm}$ IBA than the foliar spray method at $1000 \mathrm{ppm}$ IBA. These results suggest that for wall germander, IBA application by the foliar spray method is equal or superior to the talc dip method presently in widespread use in the horticulture industry.

$\mathrm{W}$ all germander is a woody subshrub in the Lamiaceae family native to the Mediterranean Basin. It bears small, light pink flowers in early summer and is commonly grown as a low hedge or groundcover in mild climates (Armitage, 1997; Brickell and Cathey, 2004). Wall germander can be propagated from cuttings without adding auxin, but rooting is more rapid and uniform with the application of 1000-3000 ppm IBA (Dirr and Heuser, 2006).

Auxins are a class of plant growth regulators that affect many plant physiological processes, including rhizogenesis. The endogenous auxin indole-3-acetic acid plays the most noteworthy role, although there are several other endogenous auxins including IBA, and many synthetic analogs with auxinic effects (Taiz et al., $2015)$. For many years, talc- or waterdiluted IBA formulations applied to the basal end of cuttings have been used in the nursery industry to induce rhizogenesis in cuttings for plant propagation (Hartmann et al., 2011).

The application of dilute liquid auxin directly to the foliage of cuttings could reduce production costs,

Department of Horticulture and Crop Science, California Polytechnic State University, 1 Grand Avenue, San Luis Obispo, CA 93407

${ }^{1}$ Corresponding author. E-mail: bkhoover@calpoly. edu.

https://doi.org/10.21273/HORTTECH03891-17 increase efficiency, and simplify compliance with workplace safety regulations (Blythe et al., 2004a). Workers exposed to even low concentrations of aerosolized talcum powder are legally required to wear personal protective equipment including a respirator, gloves, protective eyewear, long sleeves, and long pants (Brooker Chemical Corp., n.d.; OHP, Inc., 2010). The efficacy of foliar spray application of IBA to promote rhizogenesis has only been reported for a few species and the method has had mixed results (Blythe et al., 2002; Drahn, 2007). The method has been effective in the propagation of chrysanthemum (Chrysanthemum pacificum) and forsythia (Forsythia xintermedia 'Lynwood Gold') cuttings but has been less successful with crape myrtle (Lagerstroemia indica), glossy abelia (Abelia xgrandiflora), and weeping fig (Ficus benjamina) cuttings (Blythe et al., 2003b, 2004a; Kroin, 1992). Commercial growers might consider foliar IBA rates and species efficacy proprietary information, leading to anecdotal accounts that lack data. Furthermore, suppliers of unrooted cuttings might make recommendations for foliar auxin application without providing supporting data (Yoder Brothers, 2004). At present there is no detailed research on the effects of foliar auxin application in many plant species, including wall germander or any other species in the Lamiaceae. The objective of this study was to evaluate the foliar auxin spray method for rooting wall germander cuttings.

\section{Materials and methods}

Semi-hardwood terminal cuttings of wall germander were collected on 23 Sept. 2016 for the first experiment and 25 Mar. 2017 for the second experiment. Each cutting was $\approx 8 \mathrm{~cm}$ long, with two or three nodes. Exclusion criteria included the presence of flowers or flower buds, branches, disease symptoms, mechanical damage, or atypical growth. Cuttings were treated with 0,1000 , or 3000 ppm IBA, either as a foliar spray of water-diluted potassiumIBA salts (IBA Water Soluble Salts; Hortus USA Corp., New York, NY) until runoff or as a basal dip in talcdiluted IBA powder (Rhizopon; Phytotronics, Earth City, MO). Control treatments were deionized water for the foliar spray and $100 \%$ pure talc for the basal quick-dip. To mimic the proposed commercial application, foliar treatments were applied after cuttings were stuck, whereas talc treatments were applied before sticking. Cuttings were stuck in 2:1 sphagnum peat (Sunshine Select Canadian Sphagnum Peat Moss; Sun Gro Horticulture, Agawam, MA) and coarse perlite (NorCal, Richmond, CA) in square rose pots [2.25 inches top width, 3.25 inches depth, and 185 $\mathrm{cm}^{3}$ volume (SR225X; McConkey Co., Sumner, WA)]. Each pot was an experimental unit and received one cutting. The pots were placed in a greenhouse with daytime mist for

\begin{tabular}{llll}
\hline $\begin{array}{l}\text { Units } \\
\text { To convert U.S. to SI, } \\
\text { multiply by }\end{array}$ & U.S. unit & SI unit & $\begin{array}{l}\text { To convert SI to U.S., } \\
\text { multiply by }\end{array}$ \\
\hline 2.54 & inch(es) & $\mathrm{cm}$ & 0.3937 \\
25.4 & inch(es) & $\mathrm{mm}$ & 0.0394 \\
6.4516 & inch $^{2}$ & $\mathrm{~cm}^{2}$ & 0.1550 \\
16.3871 & inch $^{3}$ & $\mathrm{~cm}^{3}$ & 0.0610 \\
28,350 & $\mathrm{Oz}$ & $\mathrm{mg}$ & $3.5274 \times 10^{-5}$ \\
1 & ppm & ${ }^{\circ g} \cdot \mathrm{g}^{-1}$ & 1 \\
$\left({ }^{\circ} \mathrm{F}-32\right) \div 1.8$ & ${ }^{\circ} \mathrm{F}$ & ${ }^{\circ} \mathrm{C}$ & $\left({ }^{\circ} \mathrm{C} \times 1.8\right)+32$
\end{tabular}


$20 \mathrm{~s}$ every $3 \mathrm{~min}$ in a randomized complete block design. Mean atmospheric temperatures near the cuttings were $\approx 77 \pm 10^{\circ} \mathrm{F}$ and substrate temperatures were $\approx 76 \pm 10^{\circ} \mathrm{F}$. In
Fall 2016, the first three blocks were harvested after $69 \mathrm{~d}$ on 1 Dec. 2016 , whereas the remaining four blocks were harvested after $75 \mathrm{~d}$ on 7 Dec. 2016. In Spring 2017, two blocks were
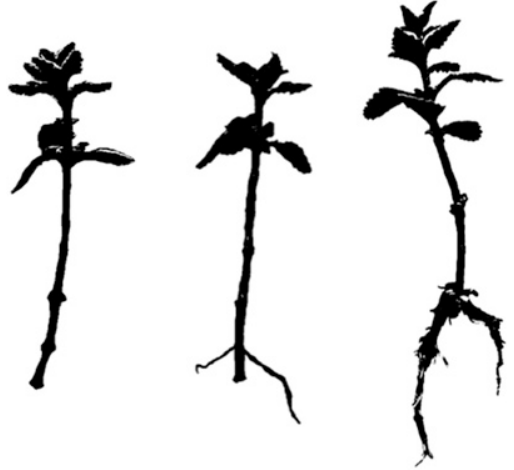

0

1

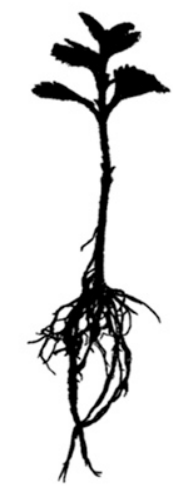

3

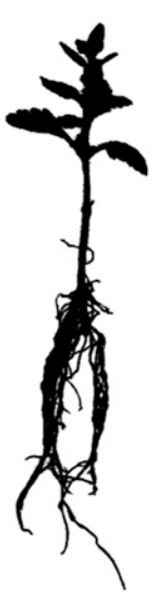

4

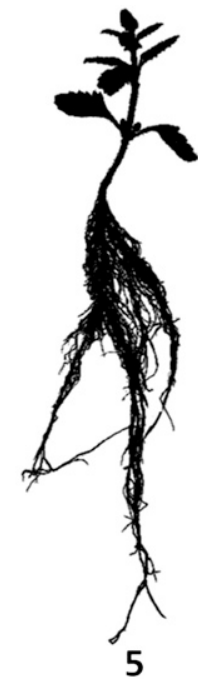

5

Fig. 1. A 0 through 5 rooting index for wall germander cuttings $(0=$ no roots, $1=$ one or two roots, 2 = more than two roots but minimal rooting, $3=$ moderate rooting but not sufficient for transplanting, 4 = sufficient roots for transplanting, and $\mathbf{5}$ = optimum roots for transplanting).

harvested after $61 \mathrm{~d}$ on 25 May 2017, two blocks after $66 \mathrm{~d}$ on 30 May 2017, and three blocks after $68 \mathrm{~d}$ on 1 June 2017. The harvests were staggered when the initial blocks did not show sufficient root growth or when time constraints precluded a single harvest.

Roots were washed with a spray nozzle and then dried. A rooting index was assigned on a 0 to 5 scale: $0=$ no roots, $1=$ one or two roots, $2=$ more than two roots but minimal rooting, 3 = moderate rooting but not sufficient for transplanting, $4=$ sufficient roots for transplanting, and 5 = optimum roots for transplanting (Fig. 1). The roots were then excised from the cutting onto a transparent cellulose acetate sheet with care to avoid overlapping roots and scanned at 600 dpi against a white background (Perfection V19; Epson America, Long Beach, CA). Root tissue was oven dried at $72{ }^{\circ} \mathrm{C}$ for $48 \mathrm{~h}$, then weighed to determine dry weight. Scans were analyzed with ImageJ (version 1.50a; National Institutes of Health, Bethesda, MD) to determine mean root two-dimensional area

Table 1. Analysis of variance table for rooting data from a repeated experiment with wall germander cuttings treated with 0 , 1000 , or $3000 \mathrm{ppm}\left(\mu \mathrm{g} \cdot \mathrm{g}^{-1}\right)$ indole-3-butyric acid applied via a talc dip or a foliar spray $(n=7)$. The leftmost column contains the four root response metrics, each with the factors analyzed in the model: block, auxin rate, auxin application method, and the interaction between auxin rate and application method.

\begin{tabular}{|c|c|c|c|c|c|c|c|c|}
\hline \multirow[b]{2}{*}{ Source of variation } & \multicolumn{4}{|c|}{ Fall 2016} & \multicolumn{4}{|c|}{ Spring 2017} \\
\hline & df & SS & MS & $P$ & df & SS & MS & $P$ \\
\hline \multicolumn{9}{|l|}{ Two-dimensional root area $\left(\mathrm{cm}^{2}\right)$} \\
\hline Auxin rate & 2 & $1,869.31$ & 934.66 & $<0.001$ & 2 & 968.59 & 484.30 & $<0.001$ \\
\hline Application method & 1 & 517.87 & 517.87 & 0.002 & 1 & 7.38 & 7.38 & 0.552 \\
\hline Auxin rate $\times$ application method & 2 & 129.22 & 64.61 & 0.241 & 2 & 88.42 & 44.21 & 0.132 \\
\hline Block & 6 & 643.62 & 107.27 & 0.493 & 6 & $18,761.29$ & $3,126.88$ & $<0.001$ \\
\hline Auxin rate & 2 & $8,387.29$ & $4,193.65$ & $<0.001$ & 2 & $27,564.14$ & $13,782.10$ & $<0.001$ \\
\hline Application method & 1 & $3,828.60$ & $3,828.6$ & $<0.001$ & 1 & $1,000.60$ & $1,000.60$ & 0.112 \\
\hline Auxin rate $\times$ application method & 2 & 808.62 & 404.31 & 0.044 & 2 & $5,090.05$ & $2,545.03$ & 0.004 \\
\hline Error & 30 & $3,486.67$ & 116.22 & & 30 & $11,212.71$ & 373.76 & \\
\hline Auxin rate $\times$ application method & 2 & 0.0004 & 0.0002 & 0.317 & 2 & 0.0004 & 0.0002 & 0.122 \\
\hline Error & 30 & 0.0056 & 0.0002 & & 30 & 0.0026 & 0.0000 & \\
\hline \multicolumn{9}{|l|}{ Rooting index ( 0 to 5 scale $)$} \\
\hline Block & 6 & 11.33 & 1.89 & 0.316 & 6 & 25.90 & 4.32 & $<0.001$ \\
\hline Auxin rate & 2 & 30.05 & 15.03 & 0.001 & 2 & 19.61 & 9.81 & $<0.001$ \\
\hline Application method & 1 & 9.52 & 9.52 & 0.018 & 1 & 0.38 & 0.38 & 0.440 \\
\hline Auxin rate $\times$ application method & 2 & 4.62 & 2.31 & 0.237 & 2 & 1.33 & 0.67 & 0.355 \\
\hline Error & 30 & 45.81 & 1.53 & & 30 & 18.66 & 0.62 & \\
\hline
\end{tabular}

SS = sum of squares; MS = mean squares. 
(square centimeters) for each cutting. The contrast of the original images was first enhanced by $0.2 \%$, then the images were converted to binary, with roots as black pixels and background as white pixels. Two-dimensional root area was defined as the total area of black pixels. The root scans were also used to assess primary root count, which was defined as the number of primary roots longer than $3 \mathrm{~mm}$ arising from the basal end of the cutting. This threshold was set because roots smaller than $3 \mathrm{~mm}$ were often difficult to distinguish from undifferentiated callus.

Data were assessed for normality via residual probability plots and analyzed with a three-factor analysis of variance followed by Tukey's honestly significant difference tests as applicable $[\alpha=0.05$ (JMP version 12 Pro; SAS Institute, Cary, NC)].

\section{Results}

BLOCK EFFECTS. There were significant block effects for twodimensional root area, primary root count, root dry weight, and rooting index in the Spring 2017 experiment. These effects may have been due to a moisture gradient resulting from air circulation fans blowing mist more heavily to one side of the bench than the other, from the staggered harvest dates, or from edge effects. However, because each block contained one of each treatment, the potential effects of these extraneous variables were evenly distributed among all the treatments. There were no secondary or tertiary interactions involving block effects.

TWO-DIMENSIONAL ROOT AREA. In the Fall 2016 experiment, auxin concentration $(P<0.001)$ and the auxin
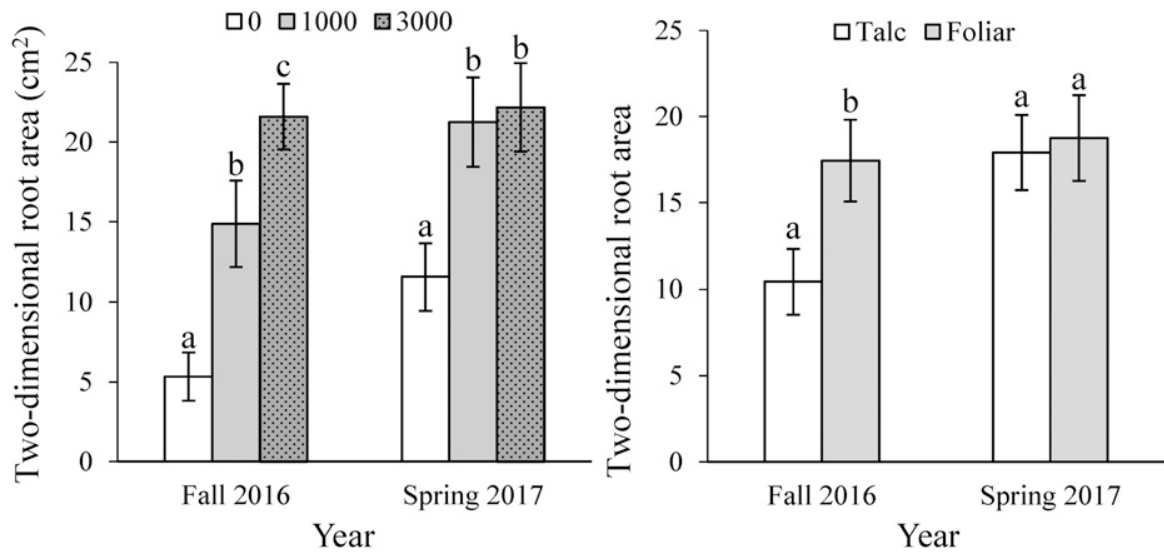

Fig. 2. Two-dimensional root area data for wall germander cuttings receiving indole-3-butyric acid treatments of 0,1000 , or $3000 \mathrm{ppm}$ applied as a foliar spray or talc dip. On each chart, treatments not sharing a letter in a year are significantly different according to a Tukey honestly significant difference test at $P<0.05$ $(n=7) ; 1 \mathrm{ppm}=1 \mu \mathrm{g} \cdot \mathrm{g}^{-1}, 1 \mathrm{~cm}^{2}=0.1550 \mathrm{inch}^{2}$.

application method $(P=0.002)$ had significant effects on two-dimensional root area (Table 1). Root area increased with increasing auxin concentration, and the foliar spray method led to larger root areas than the talc dip method at all concentrations (Fig. $2)$. In the Spring 2017 experiment, auxin concentration $(P<0.001)$, but not the application method, had a significant effect, with root area increasing as the auxin concentration increased from 0 to 1000 or $3000 \mathrm{ppm}$ IBA. The largest root areas were achieved with a foliar spray of 1000 ppm IBA or a talc dip of 3000 ppm IBA (Table 2).

Primary root count. In the Fall 2016 experiment, there was a significant interaction between auxin concentration $(P<0.001)$ and the auxin application method $(P<0.001)$ (Table 1). Root count increased with increasing auxin concentration, but the foliar spray at $1000 \mathrm{ppm}$ led to root counts comparable with that of the talc dip at 3000 ppm (Fig. 3). The foliar spray method at 3000 ppm led to the highest root counts (Table 2). In Spring 2017, only auxin concentration had a significant effect $(P<0.001)$, with primary root count increasing as the auxin concentration increased from 0 to 1000 to 3000 ppm IBA (Fig. 4). The foliar spray method reached its maximum number of primary roots at $1000 \mathrm{ppm}$ IBA, whereas the talc dip did so at 3000 ppm IBA (Table 2 ).

ROOT DRY WEIGHT. In the Fall 2016 experiment, auxin concentration $(P<0.001)$ and the application method $(P=0.013)$ had significant effects on root dry weight (Table 1). Increasing auxin concentration led to

Table 2. Adventitious rooting least square means data for wall germander cuttings receiving indole-3-butyric acid (IBA) treatments of 0,1000 , or $3000 \mathrm{ppm}$ applied as a foliar spray or talc dip $(n=7)$.

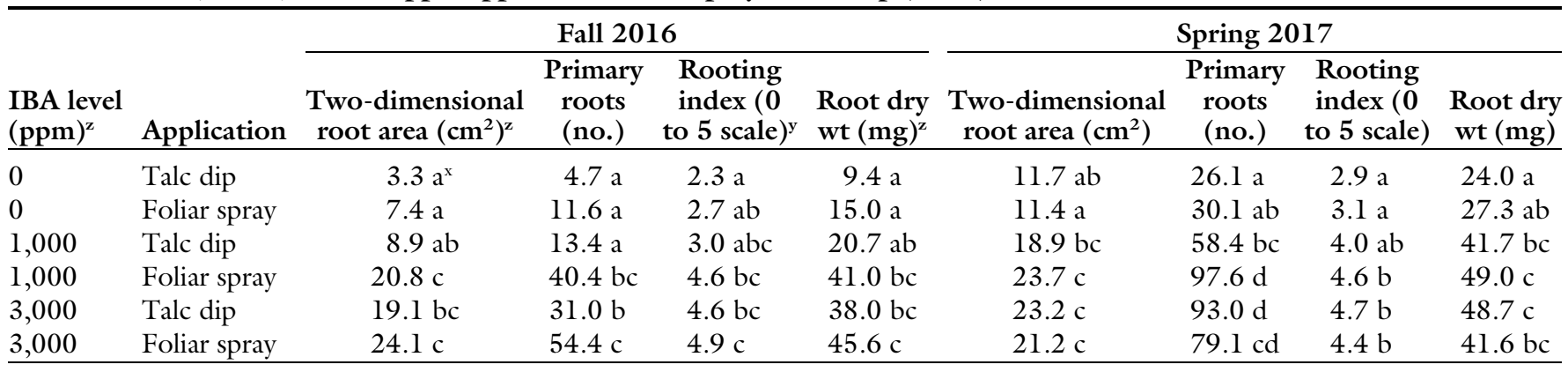

${ }^{\mathrm{z}} 1 \mathrm{ppm}=1 \mu \mathrm{g} \cdot \mathrm{g}^{-1} ; 1 \mathrm{~cm}^{2}=0.1550$ inch $^{2} ; 1 \mathrm{mg}=3.5274 \times 10^{-5} \mathrm{oz}$.

${ }^{\mathrm{y}} 0=$ no roots; $1=$ one or two roots; $2=$ more than two roots but minimal rooting; $3=$ moderate rooting but not sufficient for transplanting; $4=$ sufficient roots for transplanting; and 5 = optimum roots for transplanting.

${ }^{\mathrm{x}}$ Treatments not sharing any letters in a column are significantly different according to Tukey honestly significant difference tests at $P \leq 0.05$ 


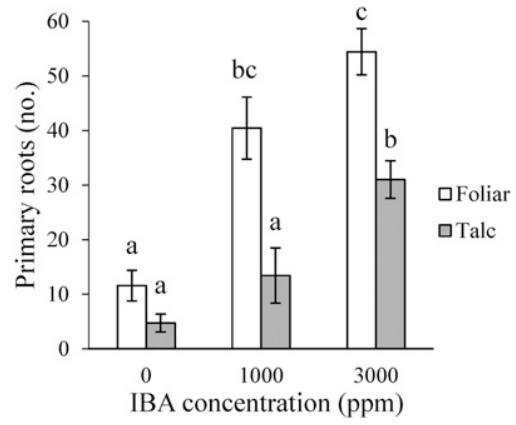

Fig. 3. Primary root count data for wall germander cuttings receiving indole-3-butyric acid (IBA) treatments of 0,1000 , or $3000 \mathrm{ppm}$ applied as a foliar spray or talc dip (Spring 2017). Columns not sharing a letter are significantly different according to a Tukey honestly significant difference test at $P \leq \mathbf{0 . 0 5}$ $(n=7) ; 1 \mathrm{ppm}=1 \mu \mathrm{g} \cdot \mathrm{g}^{-1}$.

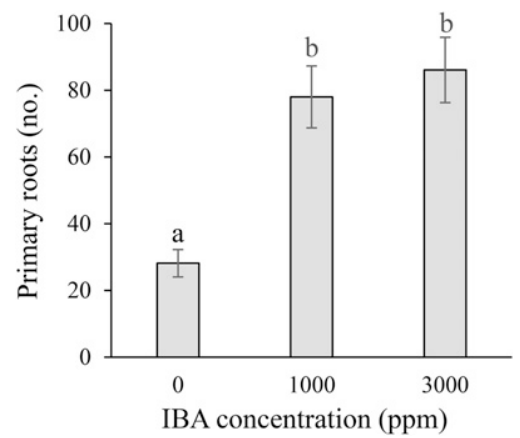

Fig. 4. Primary root count data for wall germander cuttings receiving indole-3-butyric acid (IBA) treatments of 0,1000 , or 3000 ppm (Fall 2016). Columns not sharing a letter are significantly different according to a Tukey honestly significant difference test at $P \leq \mathbf{0 . 0 5}$ $(n=7) ; 1 \mathrm{ppm}=1 \mu \mathrm{g} \cdot \mathrm{g}^{-1}$.
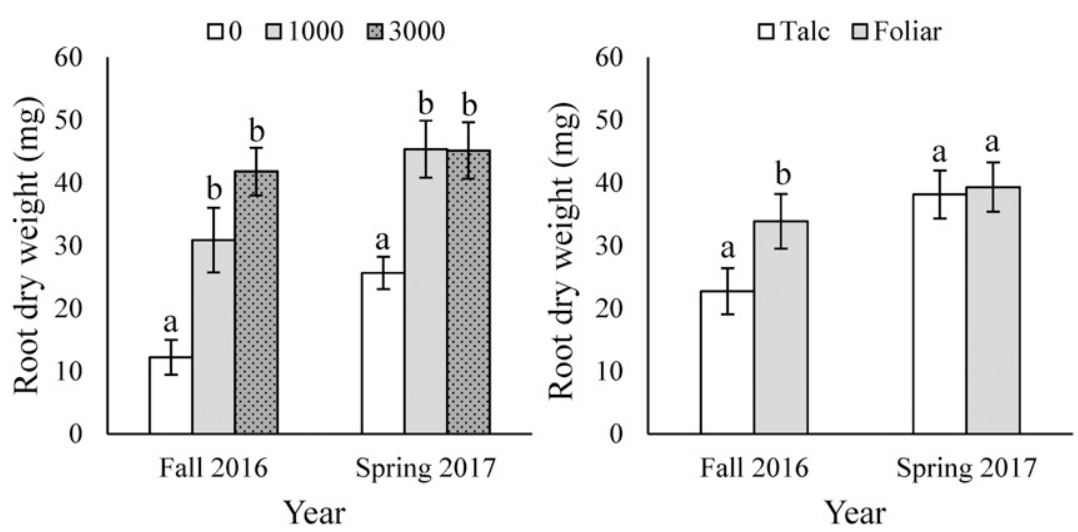

Fig. 5. Root dry weight data for wall germander cuttings receiving indole-3-butyric acid treatments of 0,1000 , or $3000 \mathrm{ppm}$ applied as a foliar spray or talc dip. On each chart, treatments not sharing a letter in a year are significantly different according to a Tukey honestly significant difference test at $P \leq 0.05(n=7)$; $1 \mathrm{ppm}=1 \mu \mathrm{g} \cdot \mathrm{g}^{-1}, 1 \mathrm{mg}=3.5274 \times 10^{-5} \mathrm{oz}$.

increasing root dry weight, and the foliar spray method led to larger root dry weight than the talc dip method (Fig. 4). However, at any given concentration, the advantage of the foliar method was not significant (Table 2). In the Spring 2017 experiment, only auxin concentration had a significant effect $(P=0.004)$, with root dry weight increasing as the auxin concentration increased from 0 to 1000 to 3000 ppm IBA (Fig. 5). However, for the foliar spray, the greatest root dry weights were achieved at $1000 \mathrm{ppm}$ IBA, with weights declining at $3000 \mathrm{ppm}$ IBA. Only the foliar spray at $1000 \mathrm{ppm}$ IBA and the talc dip at 3000 ppm IBA yielded significantly greater root dry weights than the controls (Table 2).

Rooting INDEx. In the Fall 2016 experiment, auxin concentration $(P=0.001)$ and the auxin application method $(P=0.018)$ had significant effects on rooting index (Table 1). The rooting index increased with increasing auxin concentration, and the foliar spray method yielded larger rooting indices than the talc dip method on average (Fig. 6). However, the differences due to the application method were not significant when comparing cuttings at the same concentration (Table 2). In the Spring 2017 experiment, only auxin concentration had a significant effect $(P<0.001)$, with higher concentrations yielding higher rooting indices. The foliar spray method reached a maximum rooting index at 1000 ppm, whereas the talc method reached its maximum at $3000 \mathrm{ppm}$. However, there were no significant

20 differences in rooting index among the auxin-treated plants, regardless of method of application or concentration (Table 2).

\section{Discussion}

Previous studies of foliar auxin application with other species have shown inferior or equal root response compared with the basal quick-dip method (Blythe et al., 2003a, 2003b, 2004a, 2004b). In our study, wall germander cuttings exhibited equal or superior response to the foliar spray method for all metrics and at both 1000 and 3000 ppm IBA. Consonant with Dirr and Heuser (2006), this study demonstrated improved rooting of wall germander cuttings in response to 1000 or $3000 \mathrm{ppm}$ IBA application, with lesser rooting at $0 \mathrm{ppm}$ IBA.

There were several differences in the rooting response between the Fall 2016 and Spring 2017 experiments. First, the distinct advantage of the foliar spray seen in all four root-response metrics in Fall 2016 was present only in the primary root count in Spring 2017. For the other three metrics, the foliar spray and talc dip methods were comparable. Second, in Fall 2016, there was a consistent increase in root growth with increasing auxin concentration for both the foliar spray and talc dip methods, although the increase in root growth from 0 to $1000 \mathrm{ppm}$ IBA was always greater than that from 1000 to $3000 \mathrm{ppm}$ IBA. By contrast, in Spring 2017, the foliar spray reached its maximum efficacy at $1000 \mathrm{ppm}$ IBA in each of the four metrics, declining slightly at 3000 ppm IBA, whereas the talc dip root response increased with increasing auxin concentration, reaching similar maximum efficacy at $3000 \mathrm{ppm}$ IBA.

These differences may arise from several sources. Plant material was at a different phenological stage in the fall vs. the spring. The soil moisture around the parent plants was much lower in September than in March. The daylength and sunlight intensity were greater and increasing in the spring, whereas they were lower and decreasing in the fall. Outdoor temperatures followed inverse patterns over the two experiments' growth periods.

Although the differences between the spring and fall experiments might prompt questions about seasonal changes in foliar auxin 

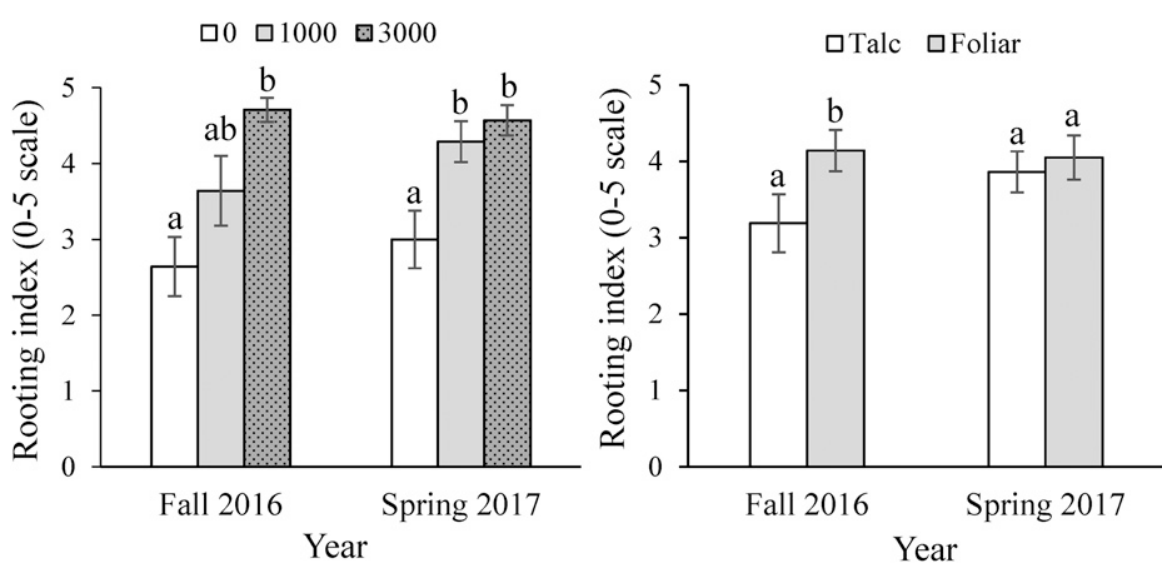

Fig. 6. Root index data $(0=$ no roots, $1=$ one or two roots, $2=$ more than two roots but minimal rooting, 3 = moderate rooting but not sufficient for transplanting, 4 = sufficient roots for transplanting, 5 = optimum roots for transplanting) for wall germander cuttings receiving indole-3-butyric acid treatments of 0,1000 , or $3000 \mathrm{ppm}$ applied as a foliar spray or talc dip. On each chart, treatments not sharing a letter in a year are significantly different according to a Tukey honestly significant difference test at $P \leq 0.05(n=7) ; 1 \mathrm{ppm}=1 \mu \mathrm{g} \cdot \mathrm{g}^{-1}$.

uptake, transport, and metabolism, they do not negate the potential advantages of using the foliar spray method. Regardless of season, our results suggest that a foliar spray treatment is at least as effective as a talc dip treatment for propagating wall germander cuttings. Because the foliar spray method offers other advantages of improved efficiency, employee well-being, and cost, it need only yield comparable root growth to be beneficial to growers. Based on these results, we recommend that growers adopt the foliar spray method for wall germander and increase trialing of the method with other species. Because of the similarity in root response between wall germander cuttings treated with 1000 and 3000 ppm IBA, we recommend testing of lower auxin concentrations to determine the lowest effective rate.

\section{Literature cited}

Armitage, A.M. 1997. Herbaceous perennial plants: A treatise on their identification, culture, and garden attributes. 2 nd ed. Stipes Publishing Co., Champaign, IL.

Blythe, E.K., J.L. Sibley, J.M. Ruter, and K.M. Tilt. 2004a. Cutting propagation of foliage crops using a foliar application of auxin. Scientia Hort. 103:31-37.

Blythe, E.K., J.L. Sibley, and K.M. Tilt. 2002. Evaluation of an alternative method of rooting hormone application in cutting propagation. Comb. Proc. Intl. Plant Prop. Soc. 52:393-399.

Blythe, E.K., J.L. Sibley, K.M. Tilt, and J.M. Ruter. 2003a. Cutting propagation with auxin applied via a stabilized or- ganic rooting substrate. Comb. Proc. Intl. Plant Prop. Soc. 53:275-283.

Blythe, E.K., J.L. Sibley, K.M. Tilt, and J.M. Ruter. 2003b. Foliar application of auxin for rooting cuttings of ornamental crops. J. Environ. Hort. 21:131-136.

Blythe, E.K., J.L. Sibley, K.M. Tilt, and J.M. Ruter. 2004b. Rooting of rose cuttings in response to foliar applications of auxin and surfactant. HortTechnology 14:479-483.

Brickell, C. and H.M. Cathey. 2004. A-Z encyclopedia of garden plants. Revised ed. DK Publishing, New York, NY.

Brooker Chemical Corp. n.d. Hormex rooting powder no. 1 agricultural use product label. Brooker Chemical Corp., Chatsworth, CA (Edinb.).

Dirr, M.A. and C.W. Heuser, Jr. 2006. The reference manual of woody plant propagation: From seed to tissue culture. 2nd ed. Varsity Press, Cary, NC.

Drahn, S.R. 2007. Auxin application via foliar sprays. Comb. Proc. Intl. Plant Prop. Soc. 57:44-48.

Hartmann, H.T., D.E. Kester, F.T. Davies, Jr., and R.L. Geneve. 2011. Hartmann and Kester's plant propagation: Principles and practice. 8th ed. Pearson, Saddle River, NJ.

Kroin, J. 1992. Advances using indole-3butyric acid (IBA) dissolved in water for rooting cuttings, transplanting, and grafting. Comb. Proc. Intl. Plant Prop. Soc. 42:489-492.

OHP, Inc. 2010. Hormodin product label. OHP, Inc., Mainland, PA.

Taiz, L., E. Zeiger, I.M. Møller, and A. Murphy. 2015. Plant physiology and development. 6th ed. Sinauer Assoc., Sunderland, MA.

Yoder Brothers. 2004. Handling unrooted perennials. Yoder Brothers, Barberton, $\mathrm{OH}$. 